\title{
EDUCAÇÃO E DIFERENÇA EM TEMPOS DE INCERTEZAS
}

\author{
IRIS VERENA OLIVEIRA
}

Doutora em Estudos Étnicos e Africanos pela Universidade Federal da Bahia, Professora do Programa de Pós-Graduação - Mestrado Profissional em Educação e Diversidade, no Departamento de Educação - DEDC XIV da Universidade do Estado da Bahia (UNEB), Gerente da Pró-Reitoria de Ações Afirmativas (UNEB). Integrante dos Grupos de Pesquisa:

Formação, Experiência e Linguagem - FEL(UNEB/CNPq); Formação em exercício de professores - FEP (UFBA/CNPq) e Currículo, cultura e diferença (UERJ/CNPq). ORCID:0000-0001-7041-3327. E-mail: irisveren@gmail.com

\section{MARIA JUCILENE LIMA FERREIRA}

Doutora em Educação pela Universidade de Brasília (UnB). Professora do Programa de Pós-Graduação - Mestrado Profissional em Educação e Diversidade, no Departamento de Educação - DEDC XIV da Universidade do Estado da Bahia (UNEB). Membro da Coordenação Colegiada do Centro Acadêmico de Educação do Campo e Desenvolvimento Territorial (CAECDT/UNEB). Vice-líder do Grupo de Pesquisa em Educação do Campo: Trabalho, Contra-hegemonia e Emancipação Humana (GEPEC); e integrante do Grupo de Pesquisa: Formação, Experiência e Linguagem (FEL) ORCID: 0000-0002-0456-3842. E-mail: mjferreira@uneb.br 


\section{EDUCAÇÃO E DIFERENÇA EM TEMPOS DE INCERTEZAS}

O presente artigo visa a ampliação e socialização do debate acerca das relações entre Educação e Diferença, oportunizando ao/a leitor/a a identificação de aproximações e divergências de interpretação das relações entre esses conceitos nas perspectivas do método materialismo histórico dialético e teorias pósestruturalistas. Ao tempo em que se propõe a evidenciar o tratamento da diferença na educação, a partir de distintas correntes epistemológicas, o artigo apresenta a irrupção da diferença na sua forma, uma vez que mobiliza vocabulário e proposições balizadas pelos principais teóricos dos paradigmas nas discussões, sem a pretensão de uma unificação da linguagem em seu formato. Finalizamos com a proposição da escuta como exercício de negociação com a diferença.

Palavras Chaves: Educação. Diferença. Epistemologia.

\section{EDUCATION AND DIFFERENCE IN TIMES OF UNCERTAINTY}

This article aims to broaden and socialize the discussion about the relations between Education and Difference, providing opportunities to the reader identification of approximations and divergences of interpretation of the relations between education and difference in the perspectives of Dialectical Historical Materialism method and Post-Structuralist Theories. At the time when it proposes to highlight the treatment of difference in education, from different epistemological currents, the article presents the irruption of the difference in its form, since it mobilizes vocabulary and propositions balized by the main Paradigms theorists in the discussions, without the pretension of a unification of language in its format. As conclusion, we summarize how each of these currents assumes their reading lens for the construction of knowledge, considering education and difference as analytical categories interpreted within the scope of each scientific field.

Key-words: Education. Difference. Epistemology.

\section{EDUCACIÓN Y DIFERENCIA EN TIEMPOS DE INCERTIDUMBRE}

Este artículo tiene como objetivo ampliar y socializar el debate sobre las relaciones entre la educación y la diferencia, proporcionando oportunidades al lector la identificación de aproximaciones y divergencias de interpretación de las relaciones entre la educación y la diferencia en las perspectivas de método materialismo histórico dialéctico y teorías post-structuralistas. En el momento en que se propone resaltar el tratamiento de la diferencia en la educación, desde distintas corrientes epistemológicas, el artículo presenta la irrupción de la diferencia en su forma, ya que moviliza el vocabulario y las proposiciones balizadas por los principales los paradigmas teóricos en las discusiones, sin la pretensión de una unificación del lenguaje en su formato. Como conclusión, resumimos cómo cada una de estas corrientes asume su lente de lectura para la construcción del conocimiento, considerando la educación y la diferencia como categorías analíticas interpretadas dentro del ámbito de cada campo científico

Palabras claves: Educación. Diferencia. Epistemología.

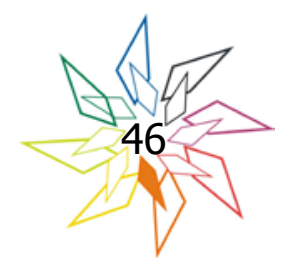




\section{EDUCAÇÃO E DIFERENÇA EM TEMPOS DE INCERTEZAS}

\section{Introdução}

O artigo propõe olhar para os conceitos de educação ediferença, pensando possibilidades de significação da escola através de paradigmas distintos. $\mathrm{O}$ exercício construído a quatro mãos, propõe um movimento de escuta, que não necessariamente conduzirá a consensos. Entendemos que o acesso as discussões possibilitam o que Paulo Freire (2004, p. 130) chamou de "processos de aprendizagem em comunhão com o outro", algo que defendemos e fazemos ao longo do texto ao apresentar concepções díspares sobre o papel da educação no tratamento da diferença.

Todavia, na atual conjuntura política e social do Brasil se evidencia amplos retrocessos de ação do conservadorismo, de ataques à democracia e ao sistema republicano federativo do país. Desde abril de 2016, quando se iniciou o processo de impeachemant da Presidenta Dilma Rousseff, eleita para o segundo mandato, com mais de 54 milhões de votos, a sociedade brasileira vivencia o fim da Secretaria Nacional de Políticas para Mulheres, Secretaria de Políticas de Promoção da Igualdade Racial, fim da Secretaria de Educação Continuada, Alfabetização, Diversidade e Inclusão (SECADI); aprovação da Emenda Constitucional, n. 95 de 16 de dezembro de 2016 para o congelamento de gastos públicos com despesas primárias do poder executivo, por um período de 20 anos; “[...] nomeação para a Secretaria da Mulher uma deputada que já presidiu a Frente Parlamentar Evangélica e é declaradamente contrária ao direito ao aborto [...]" (QUINALHA, 2016, p. 132), dentre outros aspectos vê-se em processos uma larga restrição aos direitos civis e políticos dos setores mais vulneráveis da sociedade brasileira.

Reconhecer o retrocesso não significa olhar de forma saudosista para as gestões do Partido dos Trabalhadores, uma vez que reconhecemos os limites da sua atuação no enfrentamento de questões estruturantes como o debate sobre o aborto, na perspectiva da saúde pública; as medidas de combate a violência contra a população LGBTI; ou ainda a construção de ações para a diminuição no número de jovens negros assassinados no Brasil. No campo da educação, a normatização curricular atende as demandas dos movimentos negros e indígenas, por políticas identitárias, cujos limites para emergência da diferença são evidenciados ao longo do texto. 
Atualmente é perceptível o agravamento da situação pela impossibilidade de diálogo que tem sido acompanhada de tentativas de criminalização dos movimentos sociais, crimes envolvendo militantes e a ataques as universidades e escolas, como pauta do movimento conservador, denominado Escola sem Partido. Vale ressaltar, por exemplo, o destacado do chamado "Kit Gay", no processo eleitoral para presidência em 2018, com a divulgação de informações falaciosas sobre o Projeto Escola Sem Homofobia, que sequer foi aprovado durante o governo Dilma.

Entendemos que o debate sobre Educação e Diferença é urgente no Brasil, especialmente, entre educadores, tendo em vista os frequentes ataques que apresentam cunho de intolerância religiosa, acusações a professores por realizar "doutrinação marxista" em sala de aula e o entendimento de que combater a homofobia nas escolas incentivaria a homossexualidade de crianças,

O conceito de diferença é apresentado da concepção do materialismo histórico dialético e do pós-estruturalismo. Ao tempo em que se propõe a evidenciar o tratamento da diferença na educação, a partir de distintas correntes epistemológicas, o artigo apresenta a irrupção da diferença na sua forma, uma vez que mobiliza vocabulário e proposições balizadas pelos principais teóricos dos paradigmas nas discussões, sem a pretensão de uma unificação da linguagem em seu formato.

Sendo assim, não buscamos sínteses ou acordos ao apresentar a diferença pela ótica de distintas epistemologias, o texto visa, sobretudo, elencar possibilidade de leitura sobre educação e diferença, ao pensar formas de significar o espaço escolar e as relações que nele se estabelecem reconhecendo suas desigualdades e normatizações.

No tópico "Diferença, cotidiano e trabalho" observamos ao longo das discussões apresentadas que a diferença aparece no materialismo histórico dialético como própria da condição humana e ao mesmo, na perspectiva dialética como prática social. Nesse sentido, desenvolvemos a ideia de que não é possível interpretar a diferença apenas pelas perspectivas do sujeito e nem apenas se ater às informações imediatas da realidade social concreta, mas sair em busca dos processos sociais que evidenciem essencialmente as relações sociais produzidas pelo trabalho e na luta de classe. 
Enquanto no tópico "Dobras e brechas: diferença em registro pós-estrutural" articulamos a discussão de um conto ao debate acadêmico sobre diferença no campo do currículo para pensar possibilidade de significação da escola a partir de deslocamentos e contingências que vazam em fluxos de enquadramentos normativos.

\section{Diferença, trabalho e cotidiano}

Qualquer preferência por uma ordem possível é acompanhada-geralmente de forma implícita ou inconsciente - pela aversão à ordem inversa possível. [...] (TOMASINI, 2012, p. 112).

A diferença parece ser o princípio da condição de ser humano, pois se assim não for como explicar a existência das especificidades étnico-raciais, culturais e sociais entre nós e as especificidades de outros seres vivos? Como explicar as peculiaridades das formas distintas de ver, interpretar e agir no mundo? Como explicar a existência do outro?

A diferença existe. A partir dessa afirmação, a diferença pode ser definida como um substantivo, um dado concreto no cotidiano da vida das pessoas, das relações sociais existentes. Não há como negá-la do ponto de vista de ser fato concreto. Assim como os três distintos biomas - mata atlântica, cerrado, caatinga - ocupam amplas áreas nas cinco principais regiões do país sul, sudeste, centro-oeste, norte e nordeste - caracterizando diferenças ambientais, paisagísticas e protegendo grande diversidade de flora e fauna em cada um dos biomas, também a diferença entre pessoas, é visível, é própria da realidade social.

A diferença entre pessoas, coisas, lugares, contextos, tempos e espaços, homem e natureza, o homem e outros seres vivos (mamíferos, por exemplo) é a expressão viva, real de que pertencemos a uma categoria que nos iguala, nos identifica como gênero humano, não pressupõe posições hierárquicas ou de privilégios para alguns em detrimento de outros, de favoritismo de uns sobre os outros. Partimos do princípio de que o ser humano é para si potencial de criação, de experiência, inventividade e inovação, de formas de leituras e de agir no mundo, movimentandose pari passu em duas dimensões: social e idiossincrática.

O ser humano carrega em si a condição de antecipar, pelo pensamento, a sua ação essa condição lhe é peculiar porque o difere das outras espécies animais existentes, porque 
isso o caracteriza como sujeito da história, constituído e constituinte dos processos históricos produzidos na história da humanidade. Nesse sentido coadunamos com a afirmação de Duarte (2013, p. 111) "a relação entre o indivíduo e o gênero humano sempre se realizam no interior das relações sociais concretas e históricas, nas quais cada ser humano está inserido.”

A partir desse entendimento, a diferença também pode ser entendida como virtude singular do ser humano, bem como é produzida pelas vivências sociais concretas e sua historicidade. A diferença é uma construção social, contextualizada no espaço-tempo de sua produção. Ou seja, de uma perspectiva dialética, estamos apontando dimensões distintas para a compreensão do conceito de diferença entre nós (como já afirmados - idiossincrática e social).

Ao considerarmos a diferença como produção social histórica faz-se necessário pautarmos algumas circunstâncias sob as quais essa produção se dá, trata-se das relações objetivas que se ancoram na atividade do trabalho e nas interações, valores e atitudes resultantes dessa relação, pois:

\begin{abstract}
Na atividade do trabalho, da qual decorre a construção de toda a materialidade necessária à reprodução da vida cotidiana dos seres humanos, essa relação entre subjetividade e objetividade se coloca em termos do caráter teleológico do trabalho; ou seja, trata-se de uma atividade guiada por um objetivo estabelecido pela consciência, a qual dirige a ação transformadora. Disso resulta, porém, uma realidade que possui uma dinâmica objetiva, que passa a ser comandada pelo conjunto da prática social, e não pela consciência do indivíduo. (DUARTE, 2013, p. 114).
\end{abstract}

O trabalho interpretado na perspectiva ontológica do ser social, é uma totalidade que envolve as distintas dimensões do ser humano: suas atividades nas relações com outrem, com a natureza, com suas proposições teleológicas, com a subjetividade e com a práxis social. (FERREIRA, 2015). Pressupõe, portanto, processo formativos indispensáveis à construção continuada do ser social, ou seja, diz respeito à promoção do "humano-genérico" - aquele que se constitui como síntese das relações sociais, herdeiro e preservador do desenvolvimento humano; aquele que se constitui como expressão de coletividade, humanidade e "consciência de nós".

Segundo a perspectiva ontológica sobre o trabalho, 
Antes de tudo, o trabalho é um processo entre o homem e a natureza, um processo em que o homem, por sua própria ação, media regula e controla seu metabolismo com a natureza. Ele mesmo se defronta com a matéria natural como uma força natural. Ele põe em movimento as forças naturais pertencentes à sua corporalidade, braços e pernas cabeça e mão, a fim de apropriar-se da matéria natural numa forma útil para sua própria vida. Ao atuar, por meio desse movimento, sobre a natureza externa a ele e ao modificá-la, ele modifica, ao mesmo tempo, sua própria natureza. (MARX, 1983, p. 150)

No entanto, a forma como historicamente a divisão social do trabalho foi produzida e ainda é, destorce esta concepção de trabalho e o efeito de promoção do homem-genérico acima descrito. Trata-se da perspectiva de trabalho no sistema social capitalista. E, sob esta lógica de modo de produção, a qual tem como fim último o acúmulo de riqueza pela exploração da força humana de trabalho, a diferença é marcadamente tratada por preconceitos e discriminação. (HELLER, 1989).

Dessa maneira, o potencial criador do trabalho que assume uma posição teleológica a serviço do capital produz alternativas de satisfação de suas necessidades, de modo que subsistência, produção e reprodução da vida passam, no âmbito do capital, a produzir alternativas, que são dimensionadas em si mesmas, no plano da individualidade do sujeito e não para si, na perspectiva da coletividade, da priorização do bem comum entre as pessoas. As pessoas são tratadas como clientes ou consumidores e não como sujeitos da história e de classes específicas.

Na medida em que a força humana de trabalho é expropriada do/a trabalhador/a e ao passo em que esse sujeito está submetido à realização de atividades parceladas, que ele desconhece o fim do labor que realiza, que ele está alheio ao conjunto dos procedimentos correspondentes ao produto, fruto do seu trabalho - os processos que antes, na perspectiva ontológica do trabalho se caracterizavam formativos e promotores dos processos de humanização do ser social passam a corroborar com valores de interesse do próprio sistema em vigor.

Compartilhamos, então, do seguinte pensamento:

O sistema de metabolismo social do capital nasceu como resultado da divisão social que operou a subordinação estrutural do trabalho ao capital. Não sendo consequência de nenhuma determinação ontológica inalterável, esse sistema de metabolismo social é, segundo Mészásros, o resultado de um processo historicamente constituído, em que prevalece a divisão social hierárquica que 
subsume o trabalho ao capital. Os seres sociais tornaram-se mediados entre si e combinados dentro de uma totalidade social estruturada, mediante um sistema de produção e intercâmbio estabelecido. (ANTUNES, 2009, p. 21).

Nesse sentido, o trabalho se constitui como uma das circunstâncias sob as quais a diferença é produzida na prática social, pois está diretamente relacionado às condições materiais sob as quais o trabalho se dá e aos processos de consciência do indivíduo aí produzidos. Dessa perspectiva a diferença é considerada como uma doença, como uma anormalidade, uma fraqueza ou fragilidade da pessoa que não consegue se adequar à padronização da vida social, aos modelos do que é considerado, bom, belo, aceitável, normal.

Assim inferimos que, no campo das relações sociais e a forma como o sistema capitalista se apropriou da força humana de trabalho coloca as questões de diferença como problema, indiferença, estranheza, alheia ao padrão de vida social e linguagens privilegiadas socialmente. No dizer de Tomasini (2012, p. 114): "Tudo e todos que não se encaixam no padrão social estabelecido são diferenciados. Não há limite para os rótulos: o pobre, o defeituoso, o louco, o ridículo, o velho etc."

Mais uma vez afirmamos que se por um lado, na lógica do sistema social capitalista avançase rapidamente para a negação de valores que consideram a vida e sua produção na perspectiva da comunidade e bem estar comum, por outro se amplia a ideia de que o indivíduo se basta, iludindo-se de que tudo o que precisa estar ao alcance da mão.

Vale ressaltar que:

O dinheiro tem um valor abstrato e, por isso, detém o poder de encobri todas as demais relações existentes nas mercadorias. Os seres humanos transformam-se em meros serviçais do capital; na verdade, eles se tornam mediadores entre o dinheiro e os objetos a serem comprados. (BOGO, 2008, p. 13).

Em um sistema de produção como esse, a educação é organizada e controlada para reforçar "o sistema de 'internalização'[da lógica de funcionamento e valores do capital] com todas as suas dimensões visíveis e ocultas [...]." (MÉSZÁROS, 2008, p. 47). Trata-se da internalização pelo indivíduo de naturalizar sua condição de explorado, de desprestígio social, de renegado a situações de vida e de trabalho sub-humano. É próprio do sistema hegemônico de produção, que 
a educação assuma pura e simplesmente "o quadro de valores que legitimam os interesses dominantes.” (MÉSZÁROS, 2008, p. 35).

Nesse sentido, faz-se pertinente destacar que a prerrogativa dos processos educativos formais e a vida cotidiana são da negação da diferença como dimensão humana, diferença como potencial criativo da humanidade. Tal como a definimos no terceiro parágrafo do início dessa seção, é uma característica própria do gênero humano. Mas de acordo com a lógica de interesses do capital, a diferença é uma anormalidade, irregularidade e, portanto, os sujeitos fora do padrão e da norma são excluídos socialmente, tem sua participação social negada porque nesse sistema não há uma expectativa de que a diferença floresça, desponte como possibilidade concreta de uma outra forma de viver, sentir, trabalhar e participar da vida social na sua inteireza e de acordo com suas condições, que não devem ser classificadas como melhor ou pior do que outras, apenas diferente.

Nas relações sociais comuns e próprias do âmbito do sistema capitalista de produção, a diferença seja ela marcada pela cor da pele, condição financeira, por uma deficiência física ou mental, pela opção sexual, pela opção religiosa, dentre outras - é estigmatizada. E isso faz com que as pessoas que não se enquadrem no padrão social estabelecido tenham sua identidade social reduzida, insignificante do ponto de vista da normalidade.

As pessoas constroem a sua própria imagem também pelas referências e interações que vivenciam na vida cotidiana. Assim,

É no ciclo cotidiano de enfrentamento das restrições à sua aceitação social que o indivíduo constrói sua história. O fracasso e/ou o sucesso em seguir as normas sociais têm um efeito direto sobre sua integridade psicológica. A questão de ser fiel a elas não depende só da boa vontade, mas também de sua condição. Os valores que compõem a identidade de uma sociedade vão influenciar todas as relações entre os indivíduos, relações que se estabelecem em todo o cotidiano. [...] (TOMASINI, 2012, p. 118).

Segundo Agnes Heller,

A vida cotidiana é a vida de todo homem. Todos a vivem, sem nenhuma exceção, qualquer que seja seu posto na divisão do trabalho intelectual 
e físico. Ninguém consegue identificar-se com sua atividade humanogenérica a ponto de poder desligar-se inteiramente da cotidianidade. E, ao contrário, não há nenhum homem, por mais 'insubstancial' que seja, que viva tão-somente na cotidianidade, embora essa o absorva preponderantemente. (HELLER, 1989, p. 17).

Partindo da compreensão de que o cotidiano se caracteriza pela imersão do homem em valores e práticas, pensamento e ação imediatos, rotineiros, comuns, aparentes, mas que dialeticamente também está imerso em possibilidades de transcender o cotidiano de se mobilizar na perspectiva das potencialidades do homem-genérico, coadunamos com a prerrogativa de que a diferença enfrenta e disputa espaços sociais, os sujeitos estigmatizados como pobres, velhos, negros, índios, ciganos, surdos, cegos ou com outra característica de qualquer ordem têm lutado e reivindicado o acesso e participação aos bens culturais e sociais produzidos e próprios da ação e história humana.

Ainda segundo Mészáros (2008, p. 47), parafraseando Paracelso, afirma: "A aprendizagem é a nossa própria vida, desde a juventude até a velhice", então nunca deixamos de aprender - importa para a nossa compreensão de processos educativos e sociais indagar sobre a serviço de quem estão estes processos? E qual a intencionalidade dos processos de formação e de aprendizagens? E, sobretudo, como as questões de diferença se apresentam nesses processos?

Em síntese, fazemos nossas as seguintes afirmações:

A perda da capacidade de perceber a diferença, tanto para questionála quanto para aceita-las, ela representa a crescente incapacidade de estabelecer referências de identidade - estas necessitam da percepção das diferenças contrárias. E a perda ou erosão das referências de identidade, como a de classe, afeta profundamente as possibilidades de avançar em direção à emancipação humana. (BOGO, 2008, p.13). 
Isso significa dizer que na sociedade estruturada sobre a égide da divisão de classes sociais a disputa de poder é irremediável, pois é a partir da correlação de forças que se constrói possibilidade de processos educativos na contramão da lógica do capital mediados pela história. Por isso também iniciamos nossas reflexões elegendo como epígrafe do texto o alerta de que no âmbito das relações sociais estabelecidas entre nós até aqui o mais comum é a preferência por uma ordem social em detrimento de outras possibilidades organizativas "Romper com a lógica do capital na área da educação equivale, portanto a substituir as formas onipresentes e profundamente enraizada de interncalização mistificadora por uma alternativa concreta abrangente." (MÉSZÁROS, 2008, p. 47).

Sendo assim, compreendemos que na perspectiva do materialismo histórico dialético a diferença é pensada a partir da exploração da força de trabalho e disputada socialmente no cotidiano, o que nos permite pensar a educação na contramão da lógica capitalista. Por outro caminho, as teorias pós-estruturais tratam a diferença em si, desvinculada de metanarrativas.

\section{Dobras e brechas: diferença em registro pós-estrutural}

Tudo ia mudar estudando na Henrique. André tava todo confiante, certo de que havia estourado a boa. Sabendo que todo mundo respeita sua futura escola porque os moleques de lá são neuróticos, sonhava em ser neurótico também, aproveitar que toda semana tinha porrada contra o bonde lá da Getúlio e fazer seu nome. Da região, a única escola que batia de frente com a Getúlio no porradeiro era a Henrique. A briga é parte de uma rivalidade que atravessa gerações, que hoje em dia ninguém é capaz de explicar como começou e muito menos prever como vai terminar, confronto que carrega uma série de histórias cabulosas que são contadas sem hora marcada pelas ruas de Bangu. (MARTINS, 2018, p. 45-46).

No conto "Primeiro dia", Geovani Martins relata as expectativas de André, frente ao início do ano letivo em uma nova escola. Com quase doze anos, André tinha finalizado o Ensino Fundamental I e seguia para o sexto ano, com muitos planos para próximos anos de estudo. O planejamento de sua atuação que lhe deixou insone, na véspera do primeiro dia de aula, não previa "ter estojo, sentar na frente, responder as perguntas dos professores" (MARTINS, 2018, p. 47), o que seriam "péssimas ideias pra quem pretende ser respeitado na escola." (MARTINS, 2018, p. 47) 
As expectativas do personagem do conto de Geovani Martins indicam para significações do espaço escolar distintas daquelas que costumamos ver nos textos de teoria curricular, nas leis e diretrizes voltadas para a política de currículo, direcionada para escolas de educação básica. O fragmento destoa das pretensões de formar o cidadão crítico, promover a educação emancipatória e também não diz respeito as competências e habilidades que deveria ser "adquiridas" na escola.

O trecho do conto será acionado nesse tópico do texto, como um indício da alteridade que não tem sido obliterada nas salas de aula, ao tempo em que conduzirá a apresentação das relações entre educação e diferença, na perspectiva pós-estrutural, com destaque para o debate no campo do currículo.

As preocupações do personagem André sinalizam para possibilidades de erupção da diferença na escola, a despeito dos movimentos de normatização que encontram ecos nos corredores escolares, fortalecidos por políticas curriculares que insistem na padronização através de documentos nomeados que reivindicam o "nacional" e o "comum", sem disfarçar seu intuito universalista. André significa o espaço escolar a partir das contendas entre garotos do bairro e atribui grande importância a sua performance nos primeiros dias de aula. Seus interesses fogem do lugar comum que associa a escola a possibilidade de "ser alguém na vida". Naquele contexto, interessava ser respeitado pelos garotos mais velhos, defender a escola, "ele sonhava em ser neurótico também".

A escola que aparece pela ótica de André, ora não se assemelha aquela apresentada nos documentos curriculares que insistem na mesmidade, ora apresenta os contornos do que se pretende combater. A política curricular significa a escola como espaço de ordenamentos, organizações, sequenciações, enquadramento e disciplina. (PARAÍSO, 2010) Coaduna com esse posicionamento, a valorização do conceito de identidade nos documentos curriculares. A contraposição as ações universalistas assumem o tom identitário, que denuncia desigualdades e celebra a diversidade. Por esse viés, identidade aparece pela redução ao comum, fugindo a multiplicidade como diferenciação, repetição, transgressão e improviso.

Mesmo quando consideramos identidades como "multifacetadas, fluidas, cambiantes" (MACEDO, 2014, p. 90) como denúncia à escola moderna, reeditamos o discurso universalista pela contraposição e complementação, ao acrescentar perspectivas díspares. Nessa perspectiva a identidade nomeia, outrifica e, portanto, produz "o fechamento dos sistemas de significação" (MACEDO, 2014, p. 94) produzindo o que conhecemos como diversidade. 
No debate proposto pela lente da diversidade interessam os diferentes, cujas condições distintas são marcadas por categorias fixas, em uma acepção que estabelece diferenças entre indivíduos. Na lente pós-estrutural Deleuze trata a diferença em si, como "diferenciar-se em si da coisa", como "multiplicidade substantiva". (DELEUZE, 1988) Nesse sentido, “(...) a diferença é comportar-se em relação a algo que não tem semelhante ou equivalente. A diferença é o que vem primeiro; é o motor da criação; é a possibilidade de no meio, no espaço-entre, começar a brotas hastes de rizoma" (PARAÍ́SO, 2010, p. 592)

Marlucy Paraíso (2010, p. 602), a partir de Deleuze, aponta a potencialidade de pensar a "diferença em si", fugindo a perspectiva da "diferença entre" que toma o diferente como referência, num movimento de "diferença sem o outro". Nessa mesma direção Burbules (2003, p. 178) afirma:

Esses três discursos sobre a diferença representam tanto uma crítica teórica de qualquer visão categorial da diferença quanto uma crítica política da versão liberal do pluralismo que enfatiza a compreensão e a tolerância (sim, e 'diálogo') entre as diferenças - mas diferenças que são dadas, definidas dentro dos limites que não prestam atenção suficiente às dimensões contestadas, instáveis e cambiantes da diferença à medida que as pessoas as vivem e representam. Esses discursos, de formas diferentes, embora relacionadas entre si, discutem formas de diferenças não assimiladas - diferenças que resistem à categorização ou comparação em termos do semelhante.

Ao acionar categorias estabelecidas, a partir de marcadores como raça, por exemplo, as possibilidades de existência, de luta e atuação são circunscritas no que foi estabelecido como "lugar de fala da mulher negra", num discurso com uma proposição que visa empoderar e atua dentro dos limites que aparentemente rompem. Na perspectiva apontado por Burbules o paternalismo da tolerância e a passividade das proposições de diálogo impossibilitam rasuras, traduções que poderia vazar na diferença, que não cabe em categorias mensuráveis.

Na escola de André, o personagem do conto de Geovani Martins, o recreio, esperado como um grande momento se aproxima,

O último tempo antes do recreio foi de francês, André não entendeu nada. Não conseguia parar de olhar pra monocelha do professor, além de não se interessar nem um pouco pela língua. Queria mesmo era estudar inglês, porque 
todo mundo diz que dá dinheiro, e também por conta dos videogames. Sabia que, se aprendesse a língua que falavam os personagens dos jogos preferidos da rapaziada, seria convocado por todo mundo pra jogar junto. (MARTINS, 2018, p. 47).

Para aqueles(as) que acreditam que "só o conteúdo salva", talvez nem tudo esteja perdido. Quem sabe o interesse do André pelo vídeo game possibilite que este passe a significar a escola como um espaço que lhe possibilite "ser alguém na vida"? O conto que finaliza com o jovem repetindo três vezes, no banheiro da escola, a frase: "Loura do Banheiro", talvez não nos conduza a pensar em um final feliz. Seguindo por outra trilha, poderíamos atentar para a forma como os jovens se referem ao espaço escolar, em meio aos gritos de leis, diretrizes, bases e parâmetros. Em algumas frestas as falas juvenis apontam para um cotidiano mais complexo e com espaços para diferença.

Em pesquisas realizadas no Espírito Santo, os(as) pesquisadores(as) perguntaram a estudantes da $8^{a}$ série "Quais as coisas que você detesta na escola?" e obtiveram as seguintes respostas:

\begin{abstract}
Não poder usar boné. Bagunça. Recreio. Não poder namorar. Não poder beijar na boca. Depreciação do prédio. Brincadeira fora de hora. Quadra sem cobertura descente. Não poder usar celular. Brigas. Merenda. Coordenadores. Ir para a coordenação. Professora de educação de educação física. Arroz-doce. Chamar os pais na escola. Ser obrigado a fazer fila e cantar o hino. Não poder sair mais cedo quando o professor não vem. Ter que usar o uniforme. Gente feia e pobre. Alunos do morro. Alunos e professores evangélicos. Ouvir pregação e lição de moral na sala de aula. (FERRAÇO E NUNES, 2013, p. 83).
\end{abstract}

As respostas estudantis fogem a "cordialidade" brasileira apontando para a necessidade de tratamento de questões que corriqueiramente aparecem ofuscadas na celebração da diversidade, no discurso da tolerância e tratamento superficial das situações históricas associadas a falta de equidade no Brasil. Nesse sentido, ao pensar a educação e diferença,

Não se trata apenas de suplementar um currículo padronizado com exemplos representativos de outros pontos de vista. Não se trata apenas de introduzir ou mostrar elementos de outras culturas, frequentemente fora de contexto, por seu sabor exótico ou por seu colorido. Esse tipo de diversificação do currículo pode ser benéfica, ou não, dependendo do modo como é feita. (BURBULES, 2003, p. 178). 
O movimento de diversificação curricular mencionado por Burbules, remete ao tratamento da pluralidade cultural nos Parâmetros Curriculares Nacionais, depois disso em 2003 foi sancionada a Lei 10.369/03, seguida da 11.645/08 . Nesse mesmo caminho foram aprovadas as "Diretrizes Curriculares Nacionais para a Educação das Relações ÉtnicoRaciais e para o Ensino de História e Cultura Afro-Brasileira e Africana" e as "Diretrizes Curriculares para Educação Escolar Quilombola". Na disputa pelo protagonismo de narrativas nos livros didáticos, o conceito de identidade produziu a nomeação como estancamento do fluxo de cultura como produção de sentidos, num movimento que tenta expulsar o incontrolável, em nome de projetos de reconhecimento relacionados as populações negras, indígenas e quilombolas. (APPADURAI, 2001). Tratar educação e diferença em lente pósestrutural é entender que

O compromisso da política educacional com o público - e se quisermos, com a escola pública - é, antes de tudo, um compromisso com o próprio processo de diferenciação, com as singularidades indomáveis que podem emergir. (MACEDO e RANNIERY, 2018, p. 751-752)

O compromisso com a diferenciação que reivindicam Macedo e Ranniery envolve pensar educação na contingência, proporcionando deslocamentos que levam a novas articulações. Uma atuação que pode insurgir nas brechas, a despeito e a partir da insistência do comum que tenta expulsar o incontornável. Ao considerarmos que "cada instância normativa é acompanhada de perto pelo seu próprio fracasso" (BUTLER, 2017, p. 22) entendemos que os movimentos de negociação com a diferença surgem nas brechas, calcadas em compreensões distintas do espaço escolar.

Nessas frestas é possível vislumbrar possibilidades de significação da escola como espaço de sociabilidade, encontros, desencontros e conflitos, como campo em que insurge a alteridade, que coloca o projeto de igualdade no campo da impossibilidade, uma vez que a insistência na diversidade nos leva a "diluição do sujeito no mesmo" (MACEDO, 2001, p. 99) Ao defender esse posicionamento é possível ouvir a interpelação "Mas a escola não tem que ensinar?" respondida por Elizabeth Macedo, da seguinte forma,

O compromisso da política educacional com o público - e se quisermos, com a escola pública - é, antes de tudo, um compromisso com o próprio processo de diferenciação, com as singularidades indomáveis que podem 
emergir. (MACEDO e RANNIERY, 2018, p. 751-752) (...) para uma teoria curricular comprometida com a educação, só interessa o conhecimento como ausência porque é essa ausência que nos permite a experiência de estar com o outro. (...) Mais radicalmente, o que quero é teoria curricular (e educacional) que torne abjeta a lógica da propriedade que permite ao sujeito adquirir conteúdos que o farão alguém (melhor ou pior dependendo de quem define o currículo). (MACEDO, 2017, p. 541)

Ao pensar a escola como espaço que não tem a pretensão formar um cidadão crítico, de possibilitar acesso ao conhecimento poderoso (YOUNG, 2007) ou de transformar um "ninguém" em "alguém na vida" é possível ver potência na ansiedade de André, na noite insone, antes do primeiro dia de aula "imaginando sua vida nova nas escola dos grandes", deixando pra trás o seu passado de aluno "repetente na escola primária". A importância que a instituição escolar tinha na sua vida era tão grande que além de lhe tirar o sono, permitia sonhar com suas condições no futuro próximo.

\begin{abstract}
Estava decidido que entraria na primeira briga pra defender a escola, e lutaria com tanto amor a camisa, que cairia no gosto dos moleques mais velhos. Não que gostasse de brigas ou tivesse alguma habilidade especial com socos e chutes; até então havia sido medíocre nos confrontos envolvendo moleques da sua idade, mas não tinha outro jeito, carregava a certeza de que só assim receberia o respeito de que precisava. (MARTINS, 2018, p. 46)
\end{abstract}

A fala de André atribuí grande importância ao espaço escolar. Importância tamanha que ele é capaz de enfrentar sua falta de habilidade para as brigas e seu pavor pela "Loura do Banheiro". A escola é o espaço em que ele espera conquistar o respeito dos mais velhos e, quiçá, aprender inglês pra jogar videogame. Se o impensável pelo viés das políticas curriculares conduziu André a escola - com tamanha ansiedade - resta saber se o cotidiano possibilitará o acesso à educação como exercício de negociação com a diferença, em suas fugas, vazamentos e ambivalência. Como André, estamos diante do espelho a chamar pela "Loura do Banheiro" com as seguintes opções em aberto: "fugir o mais rápido possível", "ficar maluco com a presença da menina" e "ser abduzido pra dentro do espelho". (MARTINS, 2018, p. 48) 


\section{Diferença em educação}

Atualmente no Brasil o discurso social que autoriza a eliminação do outro tem ganhado força nas redes sociais e potencializado os índices de violência. Casos de feminicídio e homofobia crescem vertiginosamente. No campo virtual cria-se uma ambiência que desqualifica o discurso das minorias e autoriza agressões e ameaças. Diante do contexto delicado vivenciado no Brasil entendemos que tratar da diferença é imprescindível.

Em 14 de março de 2018, movimentos sociais em todo o país deram visibilidade ao assassinato da vereadora Marielle Franco e seu motorista Anderson Gomes, um ano depois, a polícia ainda não forneceu informações explícitas sobre a motivações e mentores do crime. Um ano depois, os brasileiros acompanharam as notícias sobre o ataque a uma escola em Suzano, interior de São Paulo, que tirou a vida de dez pessoas. As investigações dos casos citados apontam para discursos de legitimação do ódio em que a discordância é materializada em ações com intuito de extirpar o outro.

Diante desse contexto, defendemos ao longo do texto distintas compreensões da relação entre educação e diferença pelas lentes do materialismo histórico dialético e do pósestruturalismo. Ao tratar os conceitos a partir do trabalho como perspectiva ontológica do ser social e da abertura de sistemas de significação, exercitamos ao longo do texto possibilidades de acesso a outras formas de organização do pensamento.

Para o materialismo histórico o marcador classe explica a existência da diferença, expressa como desigualdade, frente a exploração da força de trabalho, no capitalismo. Assim, a escola seria o espaço de produção de contra narrativas, de formação de consciência frente a um contexto de exploração, possibilitando a construção de caminhos para alterar essa realidade.

Aparentemente, a abordagem pós-estrutural apresenta uma perspectiva mais pessimista, uma vez que reconhece a impossibilidade de operar forma dos movimentos normativos, tão presentes no contexto escolar e baseando os projetos de reconhecimento a partir da política identitária. Entretanto, a produtividade da norma aparece em sua iterabilidade, cuja repetição não acontece da mesma forma, possibilitando vazamentos, brechas e espaços para o imponderável. Isso permite que o fluxo de significações sobre o papel da escola, por exemplo, apresente possibilidade impensadas e, por isso mesmo potentes.

Nosso intuito na construção desse artigo não foi o estabelecimento do consenso, uma vez que a centralidade do marcador classe, na abordagem materialista apresenta impossibilita 
o diálogo com os pós-estruturalistas que fogem as metanarrativas e desacreditam nas transformações estruturais conduzidas pelo sujeito de forma revolucionária. Além disso, a centralidade das discussões na diferença em si, se contrapõe aos esforços de emancipação relacionados as políticas identitárias.

Por sua vez, os materialistas refutam as análises oriundas puramente da perspectiva do sujeito - é a prática social e as relações que aí se estabelecem o elemento fundante sob o qual a diferença, por exemplo, é tratada - Tanto do ponto de vista da sua importância, reconhecimento e valor para a construção de uma vida social justa e digna, quanto do entendimento de que em outros contextos históricos, tal como atualmente ocorre, em larga medida, essa mesma prática social toma a diferença com preconceito e discriminação.

Assim, o texto se propôs a possibilidade de apresentar posicionamentos lastreados em epistemologias distintas visando romper o círculo acadêmico, no qual falamos apenas para os nossos pares, aqueles que compartilham as mesmas referências. Ao mesmo tempo em que criticamos a dificuldade de escuta, nas redes sociais, por exemplo, sem identificar as nossas práticas que envolvem a construção de bolhas de isolamento nas redes acadêmicas e virtuais. Se o intuito é fugir da saudação a diferença, que desconsidera os condicionamentos históricos e sociais e que nos coloca em lugares diferentes, construímos ao longo do texto um espaço para a escuta, algo bastante caro no contexto em que estamos inseridas.

\section{REFERÊNCIAS}

ANTUNES, Ricardo. Os sentidos do trabalho: Ensaio sobre a afirmação e a negação do trabalho. 2. ed. São Paulo: Boitempo, 2009.

APPADURAI, A. La modernidade desbordada: dimensiones culturales de la globalización. Buenos Aires: Fondo de Cultura Económica, 2001.

BOGO, Ademar. Identidade e luta de classe. São Paulo: Expressão Popular, 2008.

BURBULES, N. Uma gramática da diferença: algumas formas de repensar a diferença e a diversidade como tópicos educacionais. In: GARCIA, R. L. e MOREIRA, A. F. B. (Orgs) Currículo na contemporaneidade: incertezas e desafios. São Paulo: Cortez, 2003. 
BUTLER, J. Relatar a si mesmo. Crítica da violência ética. Belo Horizonte: Autêntica, 2017.

DELEUZE, G. Diferença e repetição. Rio de Janeiro: Graal, 1988.

DUARTE, Newton. A individualidade para si: contribuição a uma teoria histórico-crítica da formação do indivíduo. 3.ed. ver. Campinas. SP: Autores Associados, 2013.

FERRAÇO, C. E; NUNES, K. R. Currículos, culturas e cotidianos escolares: afirmando a complexidade e a diferença nas redes de conhecimentos dos sujeitos praticantes. In: FERRAÇO, C. E; CARvalho, J. M. (Orgs) Currículos, Pesquisas, Conhecimentos e Produção de Subjetividades. Petrópolis: DP\&A/ Vitória: NUPEC/UFES, 2013.

FERREIRA, Maria Jucilene Lima. Docência na escola do campo e formação de educadores: Qual o lugar do trabalho coletivo? Tese de Doutorado. Brasília: Programa de Pós-Graduação em Educação da Faculdade de Educação da Universidade de Brasília. 2015, 235p.

FREIRE, Paulo. Pedagogia do Oprimido. $38^{\mathrm{a}}$ ed. Rio de Janeiro: Paz e Terra, 2004.

HELLER, Agnes. O cotidiano e a história. Tradução COUTINHO, C. N. e KONDER, L. 3. Ed. São Paulo: Paz e Terra, 1989.

MACEDO, E. Currículo, cultura e diferença. In: LOPES, A. C., ALBA, Alicia. Diálogos curriculares entre Brasil e México. Rio de Janeiro: EdUERJ, 2014.

MACEDO, E. e RANNIERY, T. Políticas públicas de currículo: diferença e a ideia de público. Currículo sem Fronteiras, v. 18, n. 3, p. 739-759, set./dez. 2018.

MACEDO, E. Mas a escola não tem que ensinar? Currículo sem Fronteiras, v. 17, n. 3, p. 539554, set./dez. 2017.

MARTINS, G. O sol na cabeça. São Paulo: Companhia das Letras, 2018.

MÉSZÁROS, Istvan. A educação para além do capital. São Paulo: Boitempo, 2005.

PARAÍSO, M. A. Diferença no currículo. Cadernos de Pesquisa, v. 40, n. 140, p. 587-604, 2010. 
QUINALHA, Renan. "Em nome de Deus e da família": Um golpe contra a diversidade. In: JINKINGS, Ivana; DORIA, Kim; CLETO, Murilo (Orgs). Por que gritamos golpe? Para entender o impeachenent e a crise política no Brasil. São Paulo: Boitempo, 2016. p. 131 - 138 (Coleção Tinta Vermelha).

TOMASINI, Maria Elisabete Archer. Expatriação social e a segregação institucional da diferença: reflexões. In: BIANCHETTI, Lucídio; FREIRE, Ida Mara. (Orgs). Um olhar sobre a diferença: Interação, trabalho e cidadania. 12. Ed. Campinas - SP: Papirus 2012, p. 111 - 134

YOUNG, Michael. Para que servem as escolas? Educação e Sociedade, v. 28, n. 101, pp. 12871302, 2007. 